\title{
The Role of Targeted Temperature Management in Adult Patients Resuscitated from Nonshockable Cardiac Arrests: An Updated Systematic Review and Meta-Analysis
}

\author{
Lijuan Song, ${ }^{1}$ Liang Wei, ${ }^{1}$ Lei Zhang, ${ }^{2}$ Yubao Lu, ${ }^{3}$ Kaifa Wang, ${ }^{1}$ and Yongqin Li $^{1}$ \\ ${ }^{1}$ School of Biomedical Engineering, Third Military Medical University, Chongqing 400038, China \\ ${ }^{2}$ Emergency Department, Southwest Hospital, Third Military Medical University, Chongqing 400038, China \\ ${ }^{3}$ Emergency Department, Xinqiao Hospital, Third Military Medical University, Chongqing 400037, China \\ Correspondence should be addressed to Yongqin Li; leeoken@gmail.com
}

Received 29 June 2016; Revised 4 September 2016; Accepted 27 September 2016

Academic Editor: Theodoros Xanthos

Copyright ( 2016 Lijuan Song et al. This is an open access article distributed under the Creative Commons Attribution License, which permits unrestricted use, distribution, and reproduction in any medium, provided the original work is properly cited.

\begin{abstract}
Routine targeted temperature management is recommended for comatose adult patients with return of spontaneous circulation after cardiac arrest. However, the role of targeted temperature management in patients resuscitated from nonshockable cardiac arrests remains uncertain. We conducted an updated systematic review and meta-analysis to evaluate the effects of targeted temperature management in this population. Medline, EMBASE, and Cochrane databases were systematically reviewed for studies published between January 2005 and March 2016, in which targeted temperature management was compared with standard care or normothermia for adult patients resuscitated from nonshockable cardiac arrests. A total of 25 trials that included 5715 patients were identified from 10985 relevant papers. Pooled data showed that targeted temperature management not only associated with improved short-term survival $(\mathrm{RR}=1.42,95 \% \mathrm{CI}: 1.28-1.57)$ and neurological function $(\mathrm{RR}=1.63,95 \% \mathrm{CI}$ : 1.39-1.91) but also associated with improved long-term survival $(R R=1.64,95 \% C I: 1.27-2.12)$ and neurological recovery $(R R=1.42,95 \% C I: 1.07-1.90)$ in observational cohort studies. However, more frequent infectious complications were reported in hypothermia-treated patients $(\mathrm{RR}=1.46,95 \% \mathrm{CI}: 1.26-1.70)$ and the quality of the evidence ranged from moderate to very low.
\end{abstract}

\section{Introduction}

With an incidence ranging from 35 to 125 cases per 100,000 people, out-of-hospital cardiac arrest (OHCA) remains a major public health problem all over the world [1]. Despite advances in resuscitation science and standardization of advanced life support, the less than $10 \%$ overall survival rate remains unsatisfactory [2]. The presenting ECG rhythm in cardiac arrest patients may be either a shockable rhythm (ventricular fibrillation (VF) or pulseless ventricular tachycardia (VT)) or a nonshockable one (pulseless electrical activity (PEA) or asystole), depending on the etiology and downtime [3]. Epidemiologic trends suggest that the incidence of OHCA with initial nonshockable rhythms has been growing during the last two decades [4], and the prognosis of such OHCAs is poor, with a survival rate less than $5 \%$ [5].

Failure of neurological recovery is the main cause of morbidity and mortality after spontaneous circulation has been restored [6]. Earlier randomized trials demonstrated that targeted temperature management (TTM) improves cerebral recovery $[7,8]$. When the body temperature was maintained between $32^{\circ} \mathrm{C}$ and $36^{\circ} \mathrm{C}$ for 12 to $24 \mathrm{hrs}$, survival and neurological outcomes were significantly improved compared to the instances in which TTM was not performed [9]. Accordingly, routine TTM is strongly recommended for comatose adult patients with return of spontaneous circulation (ROSC) after cardiac arrest [10]. However, the level of evidence for the recommendation is different regarding the presenting initial rhythms. For patients with shockable rhythms, the evidence is based on randomized controlled trials (RCTs). For patients with nonshockable rhythms, the benefits of TTM remain conflicting and the recommendation is based on consensus of expert opinion [10].

Because OHCA patients with nonshockable initial rhythms have a lower survival rate than patients with 
shockable rhythms, RCTs in these patients will require extremely large sample sizes to test the efficacy of TTM. A prior meta-analysis published by Kim et al. [11] with pooled data through March 2010 suggested that TTM was associated with improved short-term survival in adults patients resuscitated from nonshockable OHCAs but was limited by the small sample size (14 trials, 1382 patients). After that, several large observational cohort studies (OCSs) have focused on the role of TTM in this population, reporting conflicting results [12-17]. In the current study, we aimed to conduct an updated and comprehensive systematic review and meta-analysis on the role of TTM in adult cardiac arrest patients presenting with nonshockable initial rhythms. The results of this systematic review may represent an opportunity to provide valuable information for future clinical trials [18].

\section{Methods}

2.1. Data Search. PRISMA guideline for randomized trials and MOOSE guideline for observational studies were followed for this review [19, 20]. Medline, EMBASE, and Cochrane databases were systematically reviewed for studies published between January 2005 and March 2016, in which TTM was compared with standard care or normothermia for adult patients resuscitated from nonshockable cardiac arrests. Keywords of "hypothermia" and "cooling" were used for literature search, filtered with the term "arrest" or "cardiac arrest" or "heart arrest" and "non-shockable" or "asystole" or "PEA" or "non-VF". The search strategy for electronic databases is listed in Supplemental Table 1 (in Supplementary Material available online at http://dx.doi.org/10.1155/2016/2350974). The electronic search was limited to studies on adult human subjects. References from the studies identified and other relevant review articles were also searched to identify other potentially eligible citations. The protocol (SGX2016WZ02) was waived for ethical approval by the Review Board of Third Military Medical University and the study had not been registered on websites.

2.2. Study Selection. Two reviewers (LZ and YL) independently screened the identified studies for eligibility, with discrepancies resolved by consensus. The inclusion criteria were (1) RCT or OCS; (2) studies reporting original data about the outcome (such as short-term survival or neurological outcome to hospital discharge and/or long-term survival or neurological outcome); (3) comparative studies (randomized or observational) between TTM (maintaining a targeted temperature between $32^{\circ} \mathrm{C}$ and $36^{\circ} \mathrm{C}$ ) and standard of care or normothermia (maintaining body temperature $>36^{\circ} \mathrm{C}$ with or without temperature intervention). Exclusion criteria were age less than 18 years and patients who received combined therapies, such as prehospital and hospital cooling, TTM, and percutaneous coronary intervention.

2.3. Study Outcome Definition. The primary outcomes of interest were short-term survival or neurological outcome. Favorable short-term outcomes were defined as survival or good neurologic recovery at discharge from the hospital, or until 30 days after cardiac arrest. The secondary outcomes were long-term survival or neurological outcome. Favorable long-term outcomes were defined as being alive 6 months after the event or with good neurologic recovery [21]. Good neurological recovery was defined as a Cerebral Performance Category (CPC) score of 1 or 2 . If studies reported only good neurological recovery, we considered this outcome to be CPC 1 or CPC 2 [11].

2.4. Adverse Events. The adverse events were reported as described by the study authors [9].

2.5. Assessment of the Risk of Bias and Quality of Evidence in the Included Studies. To assess the internal validity of identified RCTs, we assessed allocation sequence generation, allocation concealment, blinding of outcome assessment, exclusion of randomized participants from the analysis, comparability of groups, loss to follow-up, and other potential sources of bias using the methodology recommended by the Cochrane Collaboration [22]. As blinding of the intervention with TTM is inherently difficult or impossible, we considered blinding adequate if the outcome assessors had been blinded to the allocation group.

The quality of OCSs was assessed using the NewcastleOttawa Scale (NOS) [23]. The NOS consists of 3 categories of quality (selection, comparability, and outcome) and assigns a maximum of 4 stars for selection, a maximum of 2 stars for comparability, and a maximum of 3 stars for outcome.

The evidence was summarized by applying Grading of Recommendations Assessment, Development, and Evaluation (GRADE) levels of high, moderate, low, and very low based on the assessment of the design, limitation, inconsistency, indirectness, imprecision, and possible publication bias of the included studies using the GRADE Pro version 3.6 software [24].

2.6. Data Analysis. The meta-analysis of the included studies was performed using Review Manager 5.3 software. Individual and pooled statistics were calculated as risk ratio (RR) with $95 \%$ confidence interval (CI). The heterogeneity among the studies was quantified by chi-square test. Values of $I^{2}>$ $50 \%$ and $P<0.1$ indicated significant heterogeneity [25]. When there was no heterogeneity among the studies, pooled effect estimate was assessed using a fixed-effects model. Otherwise, a random-effects model was used.

\section{Results}

3.1. Literature Search Results and Characteristics of Included Studies. The flow diagram of literature search is detailed in Figure 1. A total of 25 studies, including 2 RCTs and 23 OCSs, were identified from 10985 relevant papers. External, internal, or combined cooling techniques were used to induce hypothermia and target core temperature was 32$34^{\circ} \mathrm{C}$. The duration of TTM was between 18 and 25 hours while normothermia was regained by either active or passive rewarming. 


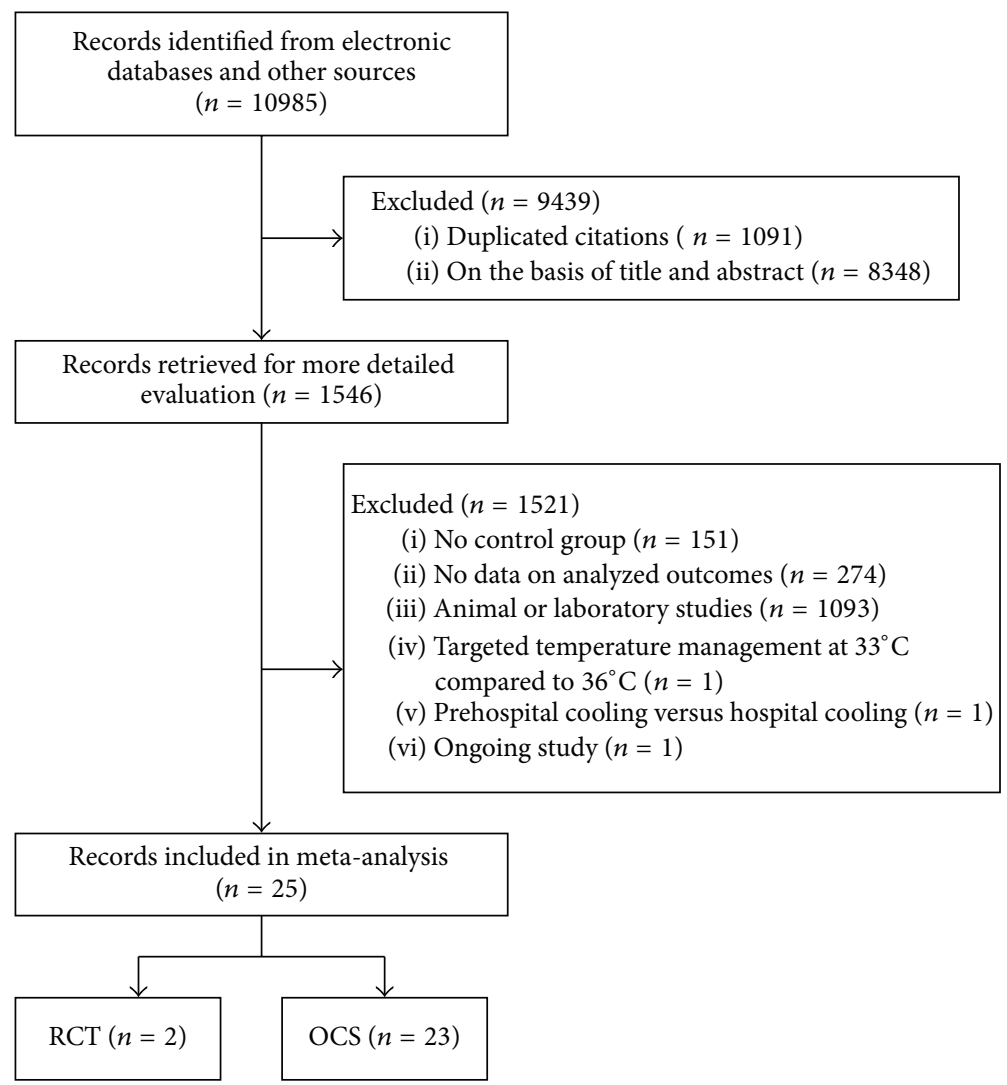

FIGURE 1: Flow diagram of the literature search.

The characteristics of the eligible studies are shown in Table 1 . The 2 RCTs were small, single center trials including 44 OHCA patients [26, 27]. Both RCT trials reported 6month survival and only 1 study reported 6-month neurological recovery. Among the 23 OCSs including 5671 patients, 17 studies reported survival to hospital discharge [14-17, 29$35,37,38,41-44], 2$ studies reported 30-day survival [28, 40], 17 studies assessed neurological function at hospital discharge $[13,14,16,17,28-31,33,34,36-39,41-43]$, and 1 study reported 14-day neurological outcome [39]. Additionally, 3 OCSs reported 6-month survival $[12,15,35]$, and 2 OCSs reported 6-month neurological recovery $[12,15]$.

3.2. The Effects of TTM on Short-Term Outcome. Nineteen studies involving 4814 patients reported short-term survival in OCSs. Test of heterogeneity was $I^{2}=49 \%$ and $P=0.009$. The pooled result showed that TTM produced significant improvements in survival ( $\mathrm{RR}=1.42,95 \% \mathrm{CI}: 1.28-1.57$, and $P<0.01$ ) using fixed-effects model (Figure 2(a)). Sensitivity analysis was performed as the $I^{2}$ value was very close to the predefined significance level. The relative risk of shortterm survival still favored TTM $(\mathrm{RR}=1.35$, 95\% CI: $1.14-$ 1.60 , and $P<0.01)$ using random-effects model. When trials with small sample size were excluded, conclusions remain unchanged.

Seventeen studies involving 4216 patients reported shortterm neurological outcome in OCSs. Test of heterogeneity was $I^{2}=34 \%$ and $P=0.08$. Meta-analysis indicated that hypothermic group had better neurological recovery than normothermic control ( $\mathrm{RR}=1.63,95 \% \mathrm{CI}: 1.39-1.91$, and $P<$ 0.01) using fixed-effects model (Figure 2(b)).

3.3. The Effects of TTM on Long-Term Outcome. Two studies reported long-term survival in RCTs. Test of heterogeneity was $I^{2}=0 \%$ and $P=0.91$. No significant difference was observed in 6-month survival ( $\mathrm{RR}=2.22,95 \% \mathrm{CI}$ : 0.56-8.85, and $P=0.26$ ) between hypothermic group and normothermic control using fixed -effects model (Figure 3(a)).

One study involving 33 patients reported long-term neurological recovery in RCTs. The result showed that TTM was not associated with good neurological outcome $(\mathrm{RR}=$ 5.29, 95\% CI: $0.27-102.49$, and $P=0.27$ ) using fixed-effects model (Figure 3(b)).

Three OCSs involving 631 patients reported long-term survival and the pooled data showed that TTM significantly improved 6-month survival ( $\mathrm{RR}=1.64$; 95\% CI: 1.27-2.12; $P<0.01$ ) using fixed-effects model (Figure 4(a)). Test of heterogeneity was $I^{2}=39 \%$ and $P=0.19$.

Two OCSs involving 597 patients reported long-term neurological recovery. Participants in the hypothermic group were more likely to reach a favorable neurological outcome $(\mathrm{RR}=1.42,95 \% \mathrm{CI}: 1.07-1.90$, and $P=0.02)$ using fixedeffects model (Figure $4(\mathrm{~b})$ ). Test of heterogeneity was $I^{2}=0 \%$ and $P=0.49$. 


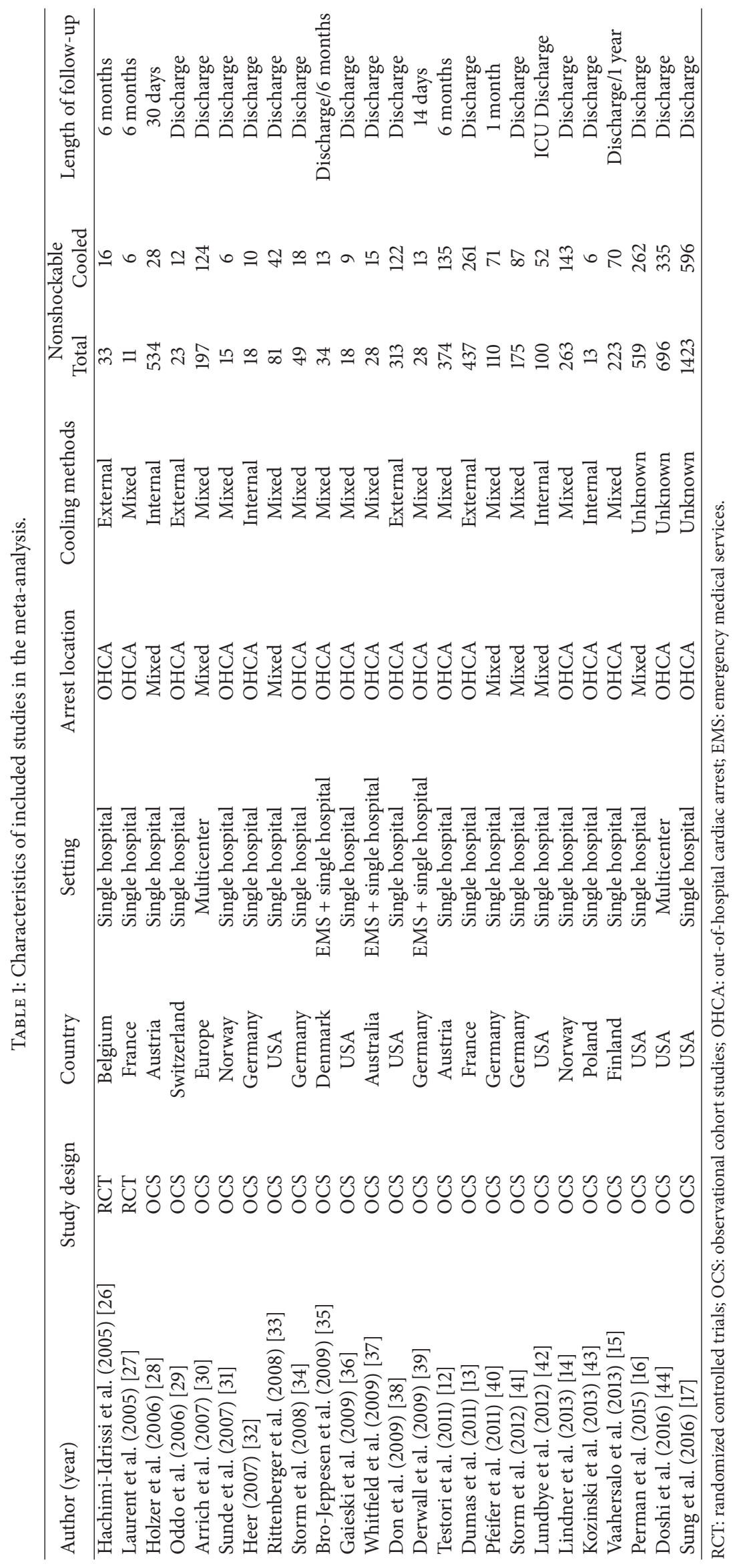




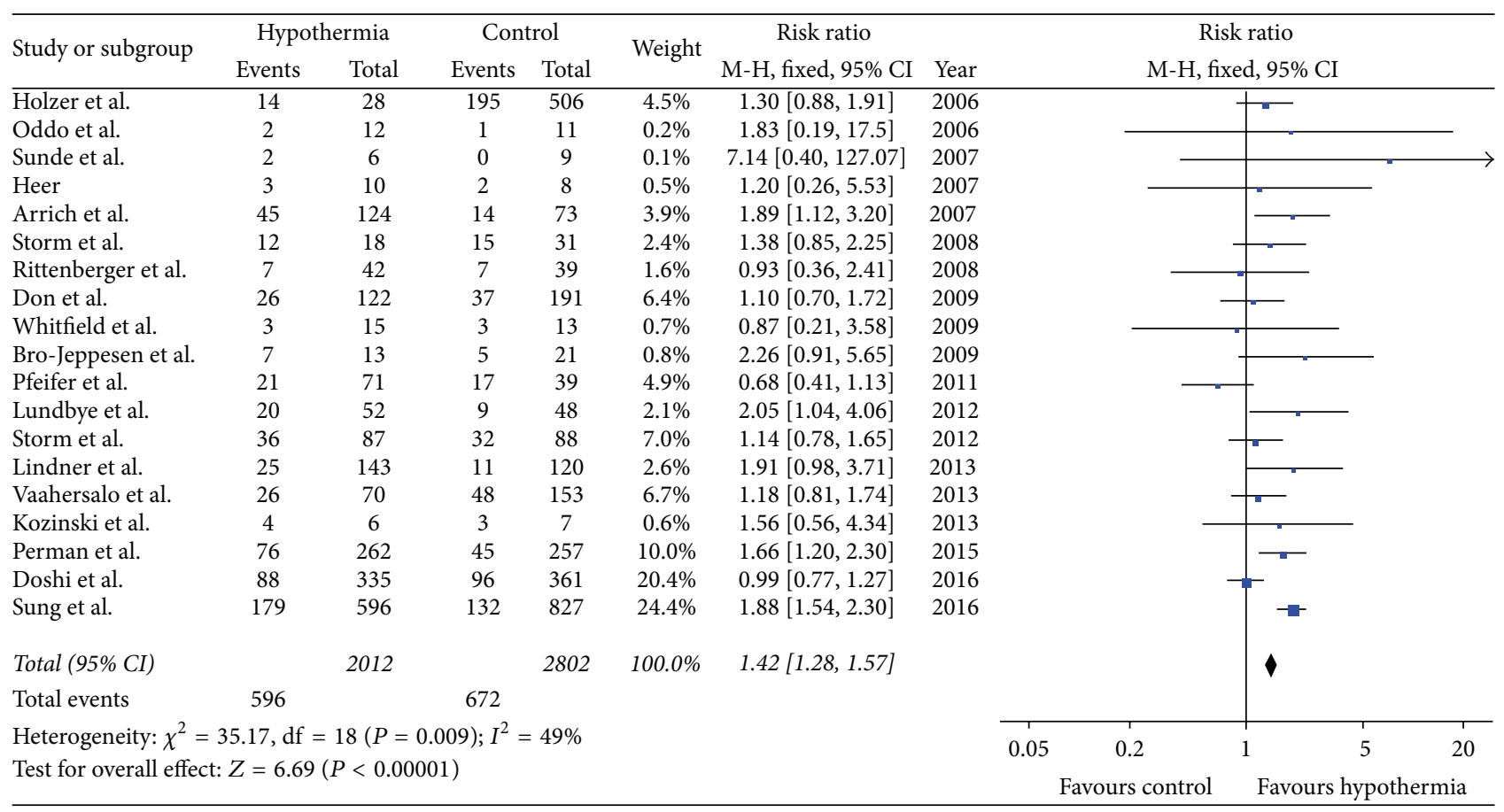

(a)

\begin{tabular}{|c|c|c|c|c|c|c|c|c|c|c|c|}
\hline \multirow{2}{*}{ Study or subgroup } & \multicolumn{2}{|c|}{ Hypothermia } & \multicolumn{2}{|c|}{ Control } & \multirow{2}{*}{ Weight } & \multicolumn{2}{|l|}{ Risk ratio } & \multicolumn{4}{|c|}{ Risk ratio } \\
\hline & Events & Total & Events & Total & & M-H, fixed, 95\% CI & Year & \multicolumn{4}{|c|}{ M-H, fixed, 95\% CI } \\
\hline Oddo et al. & 2 & 12 & 0 & 11 & $0.6 \%$ & $4.62[0.25,86.72]$ & 2006 & $\longleftarrow$ & & & \\
\hline Holzer et al. & 8 & 28 & 128 & 506 & $8.3 \%$ & $1.13[0.62,2.07]$ & 2006 & & & & \\
\hline Sunde et al. & 1 & 6 & 0 & 9 & $0.5 \%$ & $4.29[0.20,90.62]$ & 2007 & $\leftarrow$ & & & \\
\hline Arrich et al. & 35 & 124 & 14 & 73 & $9.2 \%$ & $1.47[0.85,2.55]$ & 2007 & & & & \\
\hline Rittenberger et al. & 4 & 42 & 4 & 39 & $2.6 \%$ & $0.93[0.25,3.46]$ & 2008 & $\leftarrow$ & & & \\
\hline Storm et al. & 9 & 18 & 7 & 31 & $5.7 \%$ & $2.21[1.00,4.92]$ & 2008 & & & & \\
\hline Whitfield et al. & 3 & 15 & 3 & 13 & $2.2 \%$ & $0.87[0.21,3.58]$ & 2009 & $\leftarrow$ & & & \\
\hline Don et al. & 14 & 122 & 17 & 191 & $7.3 \%$ & $1.29[0.66,2.52]$ & 2009 & & & & \\
\hline Gaieski et al. & 9 & 9 & 1 & 9 & $1.1 \%$ & $3.00[0.38,23.68]$ & 2009 & & & & \\
\hline Dumas et al. & 38 & 261 & 30 & 176 & $11.5 \%$ & $0.85[0.55,1.32]$ & 2011 & & & & \\
\hline Lundbye et al. & 15 & 52 & 6 & 48 & $5.1 \%$ & $2.31[0.97,5.46]$ & 2012 & & & & \\
\hline Storm et al. & 24 & 87 & 16 & 88 & $9.0 \%$ & $1.52[0.87,2.65]$ & 2012 & & & & \\
\hline Kozinski et al. & 1 & 6 & 1 & 7 & $0.8 \%$ & $1.17[0.09,14.92]$ & 2013 & $\leftarrow$ & & & \\
\hline Lindner et al. & 20 & 143 & 9 & 120 & $26.3 \%$ & $1.86[0.88,3.94]$ & 2013 & & & & \\
\hline Sung et al. & 83 & 596 & 41 & 827 & $13.5 \%$ & $2.81[1.96,4.02]$ & 2016 & & & & $\longrightarrow$ \\
\hline Total (95\% CI) & & 1796 & & 2420 & $100.0 \%$ & $1.63[1.39,1.91]$ & & & & & \\
\hline Total events & 320 & & 317 & & & & & & & & \\
\hline Heterogeneity: $\chi^{2}=$ & $4.36, \mathrm{df}$ & $6(P=$ & $8) ; I^{2}=$ & $34 \%$ & & & & 0.5 & 0.7 & $1 \quad 1.5$ & 2 \\
\hline Test for overall effe & $Z=5.99$ & $<0.0$ & & & & & & & Irs co & l Favours & othermia \\
\hline
\end{tabular}

(b)

FIGURE 2: The effects of targeted temperature management on short-term survival (a) and neurological outcome (b) in observational cohort studies.

3.4. Adverse Outcomes. A total of 8 studies $[13,15,17,28-$ $31,43]$ reported adverse events while only 2 studies [13, 15] compared incidence of complications between TTM and control for patients with presenting nonshockable rhythms. As shown in Figure 5, pooled data showed that infectious complications were more frequent $(\mathrm{RR}=1.46,95 \% \mathrm{CI}: 1.26-$ 1.70 , and $P<0.01$ ) in hypothermia-treated patients.
3.5. Risk of Bias and Quality in Included Studies. The 2 RCTs had substantial risks of bias according to Cochrane methodology (Supplemental Table 2). Sequence generation, allocation concealment, baseline imbalance, and sample size calculations were uncertain in 1 study [26]. Blinding of outcome assessors and baseline imbalance were not reported in the other study [27]. 


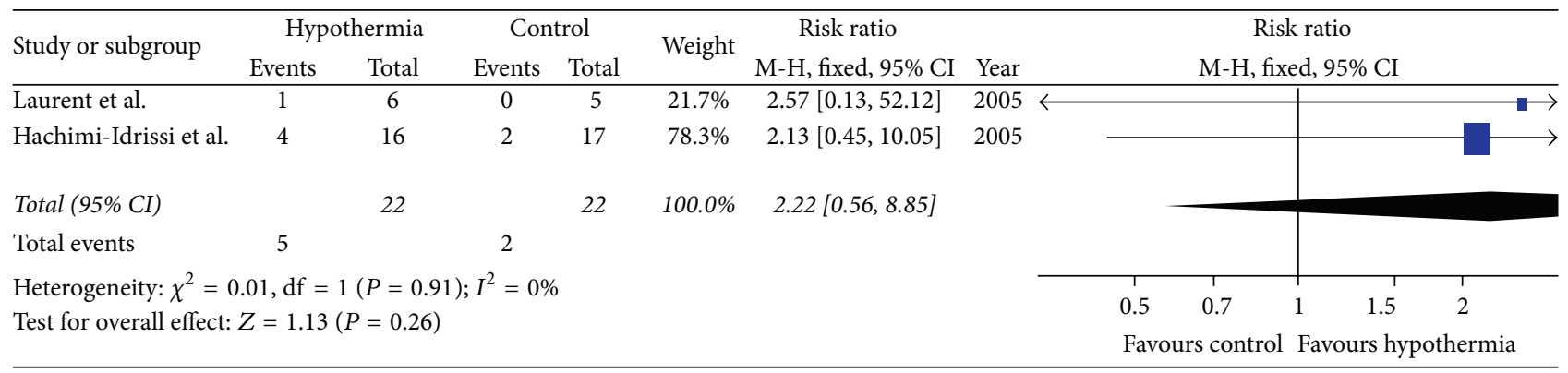

(a)

\begin{tabular}{|c|c|c|c|c|c|c|c|c|c|c|c|c|}
\hline \multirow{3}{*}{$\begin{array}{l}\text { Study or subgroup } \\
\text { Hachimi-Idrissi et al. }\end{array}$} & \multicolumn{2}{|c|}{ Hypothermia } & \multicolumn{2}{|c|}{ Control } & \multirow{2}{*}{ Weight } & \multicolumn{2}{|l|}{ Risk ratio } & \multicolumn{5}{|c|}{ Risk ratio } \\
\hline & \multirow{2}{*}{$\frac{\text { Events }}{2}$} & \multirow{2}{*}{$\begin{array}{c}\text { Total } \\
16\end{array}$} & \multirow{2}{*}{$\begin{array}{c}\text { Events } \\
0\end{array}$} & \multirow{2}{*}{$\frac{\text { Total }}{17}$} & & \multirow{2}{*}{$\frac{\text { M-H, fixed, 95\% CI }}{5.29[0.27,102.49]}$} & \multirow{2}{*}{$\begin{array}{r}\text { Year } \\
2005\end{array}$} & \multicolumn{5}{|c|}{ M-H, fixed, 95\% CI } \\
\hline & & & & & $100.0 \%$ & & & $\longleftarrow$ & & & & \\
\hline Total (95\% CI) & & 16 & & 17 & $100.0 \%$ & $5.29[0.27,102.49]$ & & & & & & \\
\hline Total events & 2 & & 0 & & & & & & & & & \\
\hline \multirow{2}{*}{\multicolumn{3}{|c|}{$\begin{array}{l}\text { Heterogeneity: not applicable } \\
\text { Test for overall effect: } Z=1.13(P=0.27)\end{array}$}} & & & & & & 0.5 & 0.7 & 1 & 1.5 & 2 \\
\hline & & & & & & & & \multicolumn{5}{|c|}{ Favours control Favours hypothermia } \\
\hline
\end{tabular}

(b)

FIGURE 3: The effects of targeted temperature management on long-term survival (a) and neurological outcome (b) in randomized controlled trials.

\begin{tabular}{|c|c|c|c|c|c|c|c|c|c|c|c|c|}
\hline \multirow{2}{*}{ Study or subgroup } & \multicolumn{2}{|c|}{ Hypothermia } & \multicolumn{2}{|c|}{ Control } & \multirow{2}{*}{ Weight } & \multirow{2}{*}{$\begin{array}{c}\text { Risk ratio } \\
\text { M-H, fixed, 95\% CI }\end{array}$} & \multirow[b]{2}{*}{ Year } & \multirow{2}{*}{\multicolumn{5}{|c|}{$\begin{array}{c}\text { Risk ratio } \\
\text { M-H, fixed, 95\% CI }\end{array}$}} \\
\hline & \multirow{2}{*}{$\begin{array}{c}\text { Events } \\
7\end{array}$} & \multirow{2}{*}{$\begin{array}{c}\text { Total } \\
13\end{array}$} & \multirow{2}{*}{$\begin{array}{c}\text { Events } \\
2\end{array}$} & \multirow{2}{*}{$\begin{array}{c}\text { Total } \\
21\end{array}$} & & & & & & & & \\
\hline Bro-Jeppesen et al. & & & & & $2.5 \%$ & $5.65[1.38,23.18]$ & 2009 & & & & & $\longrightarrow$ \\
\hline Testori et al. & 53 & 135 & 59 & 239 & $68.3 \%$ & $1.59[1.17,2.06]$ & 2011 & & & & & \\
\hline Vaahersalo et al. & 19 & 70 & 29 & 153 & $29.2 \%$ & $1.43[0.86,2.37]$ & 2013 & & & & & \\
\hline Total (95\% CI) & & 218 & & 413 & $100.0 \%$ & $1.64[1.27,2.12]$ & & & & & & \\
\hline Total events & 79 & & 90 & & & & & & & & & \\
\hline Heterogeneity: $\chi^{2}=$ & $3.28, \mathrm{df}$ & $2(P=$ & 9); $I^{2}=$ & $9 \%$ & & & & & & & & \\
\hline Test for overall effe & $Z=3.8$ & $(P=0$. & & & & & 0.1 & 0.2 & 0.5 & 1 & 2 & $5 \quad 10$ \\
\hline & & & & & & & & Favol & ontrol & & ivour & thermia \\
\hline
\end{tabular}

(a)

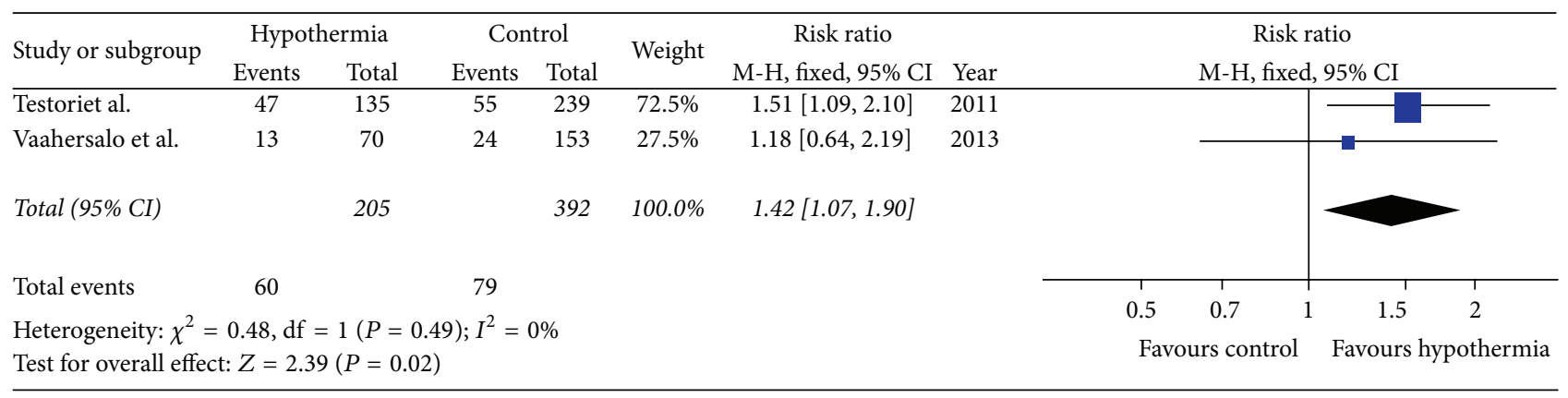

(b)

FIGURE 4: The effects of targeted temperature management on long-term survival (a) and neurological outcome (b) in observational cohort studies. 


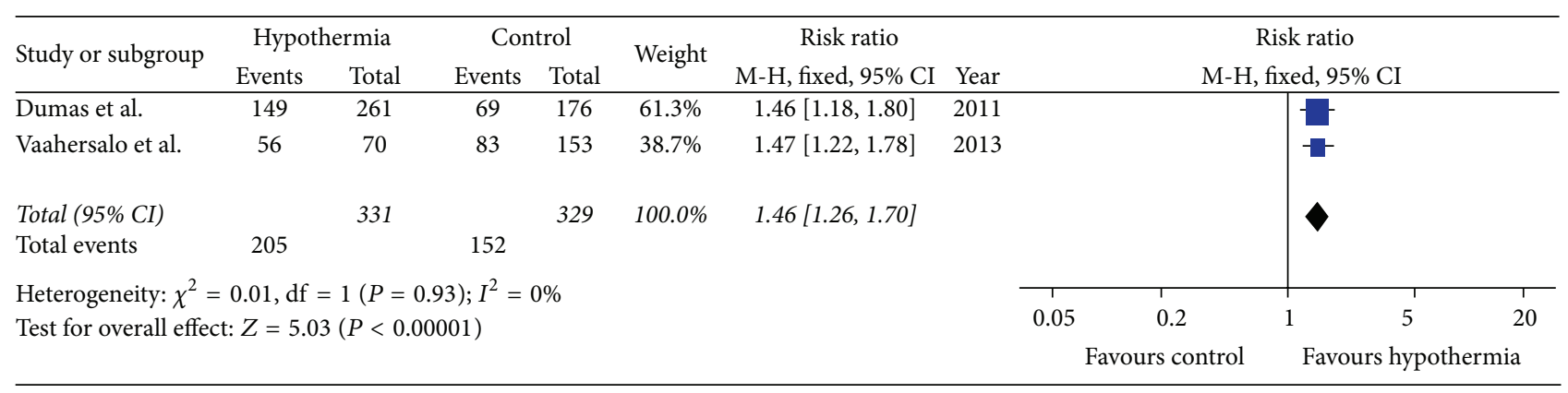

FIGURE 5: The effects of targeted temperature management on infectious complication in observational cohort studies.

The average NOS score was 7.6 and all of these studies were of high quality (NOS score > 6) (Supplemental Table 3). Among the 17 OCSs in which patients with nonshockable initial rhythms were examined by subgroups, 13 studies (56.5\%) did not report comparability of subgroup cohorts $[14,28,30-36,38-40,43]$ and 2 studies reported significant difference of characteristics between TTM and control [13, 15]. Among the 6 OCSs specifically designed to investigate the effects of hypothermia for nonshockable cardiac arrests, 5 studies $(83.3 \%)$ reported significant differences in patient demographics and arrest characteristics $[12,16,41,42,44]$.

Based on the summary of the GRADE methodology (Supplemental Table 4), the accumulated qualities were very low for primary outcome and were low for secondary outcome.

\section{Discussion}

Although TTM has been consistently demonstrated to improve outcomes for patients resuscitated from cardiac arrest with shockable rhythms, its use in subjects with nonshockable ones has produced conflicting results. In a previous meta-analysis, Kim et al. [11] examined the evidence for beneficial effects of TTM in patients who experienced nonshockable cardiac arrests using pooled data from 2 RCTs (involving 22 cases and 22 controls) and 12 OCSs (involving 412 cases and 926 controls) and concluded that TTM was associated with reduced in-hospital mortality $(\mathrm{RR}=0.84$, 95\% CI: 0.78-0.92). In a subsequent review, Sandroni et al. [45] reexamined the effects of TTM for patients who experienced nonshockable cardiac arrests in OCSs (812 cases and 1238 controls) with 3 studies $[13,41,42]$ that were not included in the previous meta-analysis. Consistently with Kim et al., pooled data showed a significant reduction in short-term mortality $(\mathrm{RR}=0.88,95 \% \mathrm{CI}$ : $0.82-0.95)$ and a smaller but significant reduction in poor neurological outcome (RR $=0.95$, 95\% CI: 0.90-0.99) in patients treated with TTM. Again, the beneficial effects of TTM on long-term survival and neurological recovery were still inconclusive since the 3 included studies did not report long-term outcomes.

In the current study, literature search resulted in 8 new additional OCSs (1618 cases and 2003 controls) but did not have additional RCTs investigating the role of TTM in nonshockable cardiac arrests. Compared with the 15 OCSs that were involved in previous meta-analysis [11, 45], the proportion of studies designed to specifically investigate the association between TTM and prognosis of nonshockable rhythms was increased (4/8 versus 2/15). Moreover, the number of studies with substantial risks of bias due to small sample size (less than 100 cases for hypothermia) was decreased (3/8 versus 12/15) in the 8 updated OCSs. Among the 8 OCSs, 7 studies $[14-17,40,43,44]$ reported shortterm (hospital discharge or 1 month) outcomes and 2 studies $[12,15]$ reported long-term (6 months or 1 year) outcomes. The updated meta-analysis, therefore, could provide a comprehensive and appraisal of the effectiveness of TTM for nonshockable cardiac arrests. Consistent with the 2 previous reviews, pooled data validated that TTM was associated with improved short-term survival and neurological recovery with high confidence. More importantly, the results suggested that TTM also significantly improved long-term survival and neurological outcomes, despite the small number of trials included in this meta-analysis.

Even though the average NOS score indicated that all of the OCSs included in this review are of high quality, the quality of evidence for TTM benefits was "very low" for short-term outcome and "low" for long-term outcome when assessed with the GRADE criteria. The following reasons may account for the relative lower quality of evidence. First, most of the studies (17/23) had substantial risks of bias because they were not specifically designed to evaluate the beneficial effects of TTM in nonshockable rhythms. The subgroup of patients with PEA/asystole was quite small in sample size and less than 20 cases of hypothermia were involved in half of these studies (9/17). None of the 9 trials individually showed a significant improvement with TTM compared with normothermic control, which was probably because of inadequate statistical power, therefore resulting in a high degree of imprecision. Second, because of the absence of randomization, differences in patient and arrest characteristics between TTM and control groups were common in these studies. The reported selection bias included sex, age, hypertension, incident location, duration of arrest, witnessed arrest, and time to ROSC $[12,13,15,16,41,42$, 44]. These discrepancies can lead to biased estimates of the treatment effects when one or more of the characteristics for which there are differences are related to the outcomes being measured. Third, the effects of TTM may be confounded by different cooling methods and rates of rewarming. For 
example, surface, invasive, and combined cooling techniques were applied and the rewarming rates ranged from 0.25 to $0.5^{\circ} \mathrm{C} / \mathrm{hr}$ in the reported studies.

Although OCSs suggested that TTM is associated with a survival and neuroprotective benefit for nonshockable cardiac arrests, no randomized trials have validated the efficacy of TTM in survivors presenting with nonshockable rhythms. An ongoing multicenter RCT study in France with blinded outcome assessment in which 584 subjects with successfully resuscitated nonshockable cardiac arrests were allocated at random to either TTM or normothermia may afford certainty of the actual benefit of TTM in this population [46].

The physiological effects of hypothermia are thought to be multifactorial, including suppression of free radicals, enzymes, excitotoxic and inflammatory reactions, preservation of the blood-brain barrier following the disruptive effects of ischemia-reperfusion, and reduction of cerebral oxygen consumption and energy metabolism [47]. Compared to dysrhythmic arrest of cardiac origin, potential causes of PEA/asystole include degeneration of a primary shockable rhythm, respiratory distress, drowning, hypovolemia, acidosis, hyper/hypokalemia, hypothermia, drug overdose, cardiac tamponade, tension pneumothorax, and coronary or pulmonary artery thrombosis [5, 48, 49]. As patients with nonshockable initial rhythms differ in pathophysiology and are associated with significantly worse short- and longterm outcomes compared to those with shockable ones with or without hypothermia $[17,18,21,50]$, identification of particular subgroups of victims who may not benefit from TTM and development of alternative approaches are an unmet medical need in ameliorating the prognosis of these patients.

Although TTM benefits patients resuscitated from nonshockable cardiac arrests, its side effects should not be ignored. The available evidence in the included 2 studies suggests an association between TTM and the risk of infectious complications, which is consistent with a previous metaanalysis that risk of pneumonia and sepsis was increased in patients treated with hypothermia [51]. Clinicians, therefore, should cautiously assess patient's risk-benefit profile during TTM.

There are several limitations of the current study. First, the overall quality of the evidence was limited due to the small number of RCTs and small sample size of OCSs. However, the problem of small OCS sample size was likely ameliorated by their large number. Second, there were considerable differences in patient and arrest characteristics, together with cooling methodology among the OCSs included in this study. But the quantitative analysis of these studies was supported by the lack of statistical heterogeneity.

\section{Conclusions}

The present study suggests that TTM is associated with improved short- and long-term outcomes for adult patients resuscitated from nonshockable cardiac arrests. At the same time, incidence of infectious complications is increased for patients treated with hypothermia.

\section{Competing Interests}

The authors declare that there is no conflict of interests regarding the publication of this paper.

\section{Acknowledgments}

This study was supported by the National Nature Science Foundation of China (NSFC81271656). The authors would like to thank Dr. Giuseppe Ristagno for his valuable contribution to the study.

\section{References}

[1] J. Berdowski, R. A. Berg, J. G. P. Tijssen, and R. W. Koster, "Global incidences of out-of-hospital cardiac arrest and survival rates: systematic review of 67 prospective studies," Resuscitation, vol. 81, no. 11, pp. 1479-1487, 2010.

[2] C. Sasson, M. A. M. Rogers, J. Dahl, and A. L. Kellermann, "Predictors of survival from out-of-hospital cardiac arrest a systematic review and meta-analysis," Circulation: Cardiovascular Quality and Outcomes, vol. 3, no. 1, pp. 63-81, 2010.

[3] D. Varvarousis, G. Varvarousi, N. Iacovidou, E. D’Aloja, A. Gulati, and T. Xanthos, "The pathophysiologies of asphyxial vs dysrhythmic cardiac arrest: implications for resuscitation and post-event management," American Journal of Emergency Medicine, vol. 33, no. 9, pp. 1297-1304, 2015.

[4] S. T. Youngquist, A. H. Kaji, and J. T. Niemann, "Beta-blocker use and the changing epidemiology of out-of-hospital cardiac arrest rhythms," Resuscitation, vol. 76, no. 3, pp. 376-380, 2008.

[5] E. P. Hess, R. L. Campbell, and R. D. White, "Epidemiology, trends, and outcome of out-of-hospital cardiac arrest of noncardiac origin," Resuscitation, vol. 72, no. 2, pp. 200-206, 2007.

[6] S. Laver, C. Farrow, D. Turner, and J. Nolan, "Mode of death after admission to an intensive care unit following cardiac arrest," Intensive Care Medicine, vol. 30, no. 11, pp. 2126-2128, 2004.

[7] S. A. Bernard, T. W. Gray, M. D. Buist et al., "Treatment of comatose survivors of out-of-hospital cardiac arrest with induced hypothermia," The New England Journal of Medicine, vol. 346, no. 8, pp. 557-563, 2002.

[8] Hypothermia after Cardiac Arrest Study Group, "Mild therapeutic hypothermia to improve the neurologic outcome after cardiac arrest," The New England Journal of Medicine, vol. 346, no. 8, pp. 549-556, 2002.

[9] J. Arrich, M. Holzer, C. Havel et al., "Hypothermia for neuroprotection in adults after cardiopulmonary resuscitation," The Cochrane Database of Systematic Reviews, vol. 2, no. 9, Article ID CD004128, 2016.

[10] C. W. Callaway, M. W. Donnino, E. L. Fink et al., "Part 8: Postcardiac arrest care: 2015 American Heart Association guidelines update for cardiopulmonary resuscitation and emergency cardiovascular care," Circulation, vol. 132, no. 18, pp. S465-S482, 2015.

[11] Y.-M. Kim, H.-W. Yim, S.-H. Jeong, M. L. Klem, and C. W. Callaway, "Does therapeutic hypothermia benefit adult cardiac arrest patients presenting with non-shockable initial rhythms?: a systematic review and meta-analysis of randomized and nonrandomized studies," Resuscitation, vol. 83, no. 2, pp. 188-196, 2012.

[12] C. Testori, F. Sterz, W. Behringer et al., "Mild therapeutic hypothermia is associated with favourable outcome in patients 
after cardiac arrest with non-shockable rhythms," Resuscitation, vol. 82, no. 9, pp. 1162-1167, 2011.

[13] F. Dumas, D. Grimaldi, B. Zuber et al., "Is hypothermia after cardiac arrest effective in both shockable and nonshockable patients?: insights from a large registry," Circulation, vol. 123, pp. 877-886, 2011.

[14] T. W. Lindner, J. Langørgen, K. Sunde et al., "Factors predicting the use of therapeutic hypothermia and survival in unconscious out-of-hospital cardiac arrest patients admitted to the ICU," Critical Care, vol. 17, article R147, 2013.

[15] J. Vaahersalo, P. Hiltunen, M. Tiainen et al., "Therapeutic hypothermia after out-of-hospital cardiac arrest in Finnish intensive care units: the FINNRESUSCI study," Intensive Care Medicine, vol. 39, no. 5, pp. 826-837, 2013.

[16] S. M. Perman, A. V. Grossestreuer, D. J. Wiebe, B. G. Carr, B. S. Abella, and D. F. Gaieski, "The utility of therapeutic hypothermia for post-cardiac arrest syndrome patients with an initial nonshockable rhythm," Circulation, vol. 132, no. 22, pp. 2146-2151, 2015.

[17] G. Sung, N. Bosson, A. H. Kaji et al., "Therapeutic hypothermia after resuscitation from a non-shockable rhythm improves outcomes in a regionalized system of cardiac arrest care," Neurocritical Care, vol. 24, no. 1, pp. 90-96, 2016.

[18] G. Biondi-Zoccai, M. Lotrionte, G. Landoni et al., "The rough guide to systematic reviews and meta-analyses," HSR Proceedings in Intensive Care \& Cardiovascular Anesthesia, vol. 3, no. 3, pp. 161-173, 2011.

[19] A. Liberati, D. G. Altman, J. Tetzlaff et al., "The PRISMA statement for reporting systematic reviews and meta-analyses of studies that evaluate health care interventions: explanation and elaboration," Annals of Internal Medicine, vol. 151, no. 4, pp. W65-W94, 2009.

[20] D. F. Stroup, J. A. Berlin, S. C. Morton et al., "Meta-analysis of observational studies in epidemiology: a proposal for reporting," The Journal of the American Medical Association, vol. 283, no. 15, pp. 2008-2012, 2000.

[21] M. Holzer, S. A. Bernard, S. Hachimi-Idrissi, R. O. Roine, F. Sterz, and M. Müllner, "Hypothermia for neuroprotection after cardiac arrest: systematic review and individual patient data meta-analysis," Critical Care Medicine, vol. 33, no. 2, pp. 414$418,2005$.

[22] J. P. T. Higgins, S. Green, and C. Collaboration, Cochrane Handbook for Systematic 445 Reviews of Interventions, Wiley Online Library, New York, NY, USA, 2008.

[23] G. A. Wells, B. Shea, D. O'Connell et al., "The NewcastleOttawa Scale (NOS) for assessing the quality of nonrandomised studies in meta-analyses," http://www.ohri.ca/ programs/clinical_epidemiology/oxford.asp.

[24] H. J. Schünemann, A. D. Oxman, J. Brozek et al., "Grading quality of evidence and strength of recommendations for diagnostic tests and strategies," The British Medical Journal, vol. 336, no. 7653, pp. 1106-1110, 2008.

[25] J. P. T. Higgins and S. Green, Cochrane Handbook for Systematic Reviews of Interventions, Version 5.0.2, The Cochrane Collaboration, London, UK, 2009.

[26] S. Hachimi-Idrissi, M. Zizi, D. N. Nguyen et al., "The evolution of serum astroglial S-100 $\beta$ protein in patients with cardiac arrest treated with mild hypothermia," Resuscitation, vol. 64, no. 2, pp. 187-192, 2005.
[27] I. Laurent, C. Adrie, C. Vinsonneau et al., "High-volume hemofiltration after out-of-hospital cardiac arrest: a randomized study," Journal of the American College of Cardiology, vol. 46, no. 3, pp. 432-437, 2005.

[28] M. Holzer, M. Müllner, F. Sterz et al., "Efficacy and safety of endovascular cooling after cardiac arrest: cohort study and Bayesian approach," Stroke, vol. 37, no. 7, pp. 1792-1797, 2006.

[29] M. Oddo, M.-D. Schaller, F. Feihl, V. Ribordy, and L. Liaudet, "From evidence to clinical practice: effective implementation of therapeutic hypothermia to improve patient outcome after cardiac arrest," Critical Care Medicine, vol. 34, no. 7, pp. 18651873, 2006.

[30] J. Arrich and European Resuscitation Council Hypothermia sfter Cardiac Arrest Registry Study Group, "Clinical application of mild therapeutic hypothermia after cardiac arrest," Critical Care Medicine, vol. 35, pp. 1041-1047, 2007.

[31] K. Sunde, M. Pytte, D. Jacobsen et al., "Implementation of a standardised treatment protocol for post resuscitation care after out-of-hospital cardiac arrest," Resuscitation, vol. 73, no. 1, pp. 29-39, 2007.

[32] C. Heer, "Hypothermia after cardiac arrest-Experiences in routine use on a medical intensive care unit," Intensivmedizin und Notfallmedizin, vol. 44, no. 5, pp. 303-307, 2007.

[33] J. C. Rittenberger, F. X. Guyette, S. A. Tisherman, M. A. DeVita, R. J. Alvarez, and C. W. Callaway, "Outcomes of a hospital-wide plan to improve care of comatose survivors of cardiac arrest," Resuscitation, vol. 79, no. 2, pp. 198-204, 2008.

[34] C. Storm, I. Steffen, J. C. Schefold et al., "Mild therapeutic hypothermia shortens intensive care unit stay of survivors after out-of-hospital cardiac arrest compared to historical controls," Critical Care, vol. 12, no. 3, article R78, 2008.

[35] J. Bro-Jeppesen, J. Kjaergaard, T. I. Horsted et al., “The impact of therapeutic hypothermia on neurological function and quality of life after cardiac arrest," Resuscitation, vol. 80, no. 2, pp. 171176, 2009.

[36] D. F. Gaieski, R. A. Band, B. S. Abella et al., "Early goaldirected hemodynamic optimization combined with therapeutic hypothermia in comatose survivors of out-of-hospital cardiac arrest," Resuscitation, vol. 80, no. 4, pp. 418-424, 2009.

[37] A. M. Whitfield, S. Coote, and D. Ernest, "Induced hypothermia after out-of-hospital cardiac arrest: one hospital's experience," Critical Care and Resuscitation, vol. 11, no. 2, pp. 97-100, 2009.

[38] C. W. Don, W. T. Longstreth Jr., C. Maynard et al., "Active surface cooling protocol to induce mild therapeutic hypothermia after out-of-hospital cardiac arrest: a retrospective before-andafter comparison in a single hospital," Critical Care Medicine, vol. 37, no. 12, pp. 3062-3069, 2009.

[39] M. Derwall, C. Stoppe, D. Brücken, R. Rossaint, and M. Fries, "Changes in S-100 protein serum levels in survivors of out-ofhospital cardiac arrest treated with mild therapeutic hypothermia: A Prospective, Observational Study," Critical Care, vol. 13, no. 2, article R58, 2009.

[40] R. Pfeifer, C. Jung, S. Purle et al., "Survival does not improve when therapeutic hypothermia is added to post-cardiac arrest care," Resuscitation, vol. 82, no. 9, pp. 1168-1173, 2011.

[41] C. Storm, J. Nee, M. Roser, A. Jörres, and D. Hasper, "Mild hypothermia treatment in patients resuscitated from nonshockable cardiac arrest," Emergency Medicine Journal, vol. 29, no. 2, pp. 100-103, 2012.

[42] J. B. Lundbye, M. Rai, B. Ramu et al., “Therapeutic hypothermia is associated with improved neurologic outcome and survival in 
cardiac arrest survivors of non-shockable rhythms," Resuscitation, vol. 83, no. 2, pp. 202-207, 2012.

[43] M. Kozinski, K. Pstragowski, J. M. Kubica et al., "ACS networkbased implementation of therapeutic hypothermia for the treatment of comatose out-of-hospital cardiac arrest survivors improves clinical outcomes: the first European experience," Scandinavian Journal of Trauma, Resuscitation and Emergency Medicine, vol. 21, no. 1, article 22, 2013.

[44] P. Doshi, K. Patel, R. Banuelos et al., "Effect of therapeutic hypothermia on survival to hospital discharge in out-ofhospital cardiac arrest secondary to nonshockable rhythms," Academic Emergency Medicine, vol. 23, no. 1, pp. 14-20, 2016.

[45] C. Sandroni, F. Cavallaro, and M. Antonelli, “Therapeutic hypothermia: is it effective for non-VF/VT cardiac arrest?" Critical Care, vol. 17, no. 2, article 215, 2013.

[46] J. B. Lascarrou, F. Meziani, A. Le Gouge et al., "Therapeutic hypothermia after nonshockable cardiac arrest: the HYPERION multicenter, randomized, controlled, assessor-blinded, superiority trial," Scandinavian Journal of Trauma, Resuscitation and Emergency Medicine, vol. 23, article 26, 2015.

[47] F. P. González-Ibarra, J. Varon, and E. G. López-Meza, “Therapeutic hypothermia: critical review of the molecular mechanisms of action," Frontiers in Neurology, vol. 3, article 4, 2011.

[48] G. K. Renkiewicz, M. W. Hubble, D. R. Wesley et al., "Probability of a shockable presenting rhythm as a function of EMS response time," Prehospital Emergency Care, vol. 18, no. 2, pp. 224-230, 2014.

[49] J. Herlitz, L. Svensson, J. Engdahl, and J. Silfverstolpe, "Characteristics and outcome in out-of-hospital cardiac arrest when patients are found in a non-shockable rhythm," Resuscitation, vol. 76, no. 1, pp. 31-36, 2008.

[50] S. W. Terman, B. Hume, W. J. Meurer, and R. Silbergleit, "Impact of presenting rhythm on short-and long-term neurologic outcome in comatose survivors of cardiac arrest treated with therapeutic hypothermia," Critical Care Medicine, vol. 42, no. 10, pp. 2225-2234, 2014.

[51] M. Geurts, M. R. Macleod, R. Kollmar, P. H. C. Kremer, and H. B. Van Der Worp, "Therapeutic hypothermia and the risk of infection: a systematic review and meta-analysis," Critical Care Medicine, vol. 42, no. 2, pp. 231-242, 2014. 


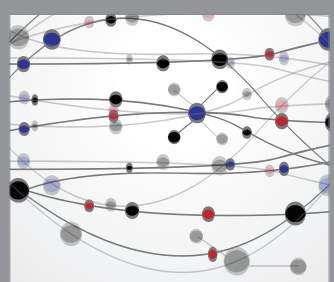

The Scientific World Journal
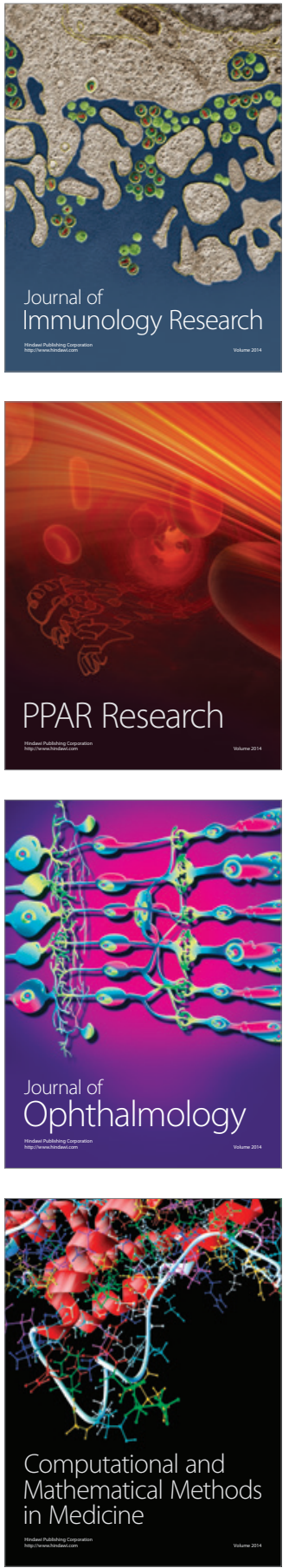

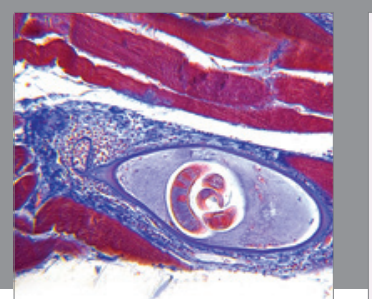

Gastroenterology Research and Practice

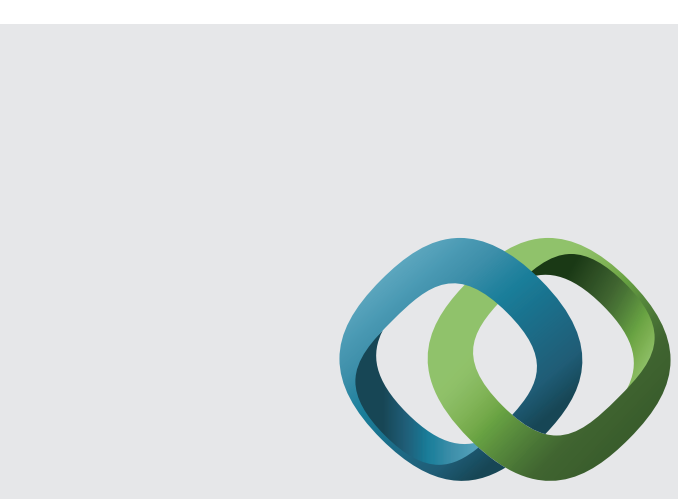

\section{Hindawi}

Submit your manuscripts at

http://www.hindawi.com
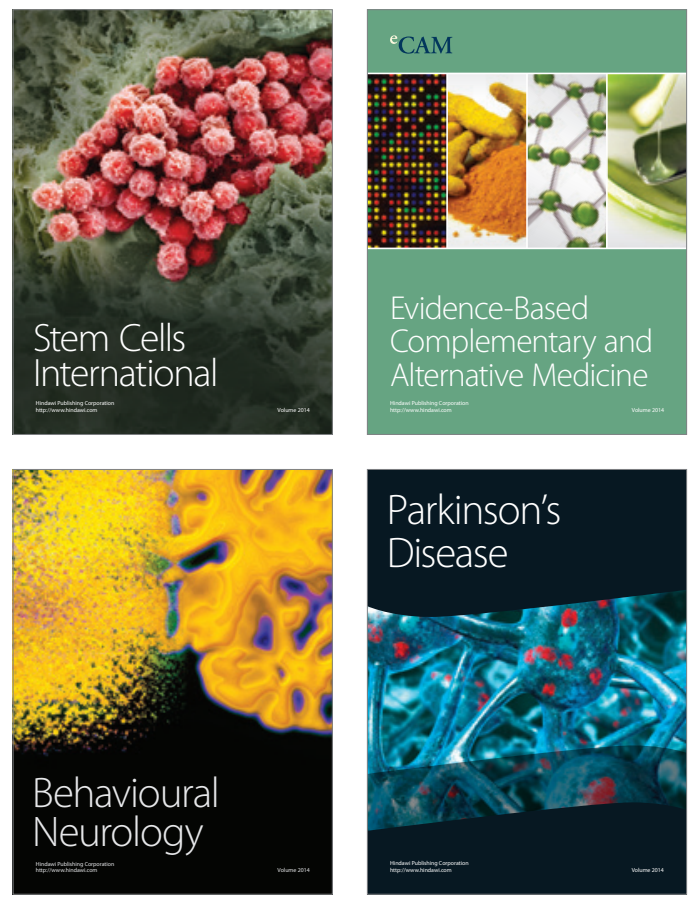
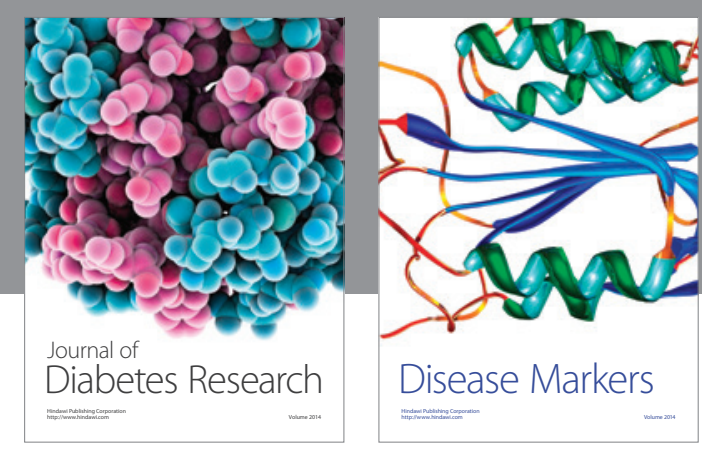

Disease Markers
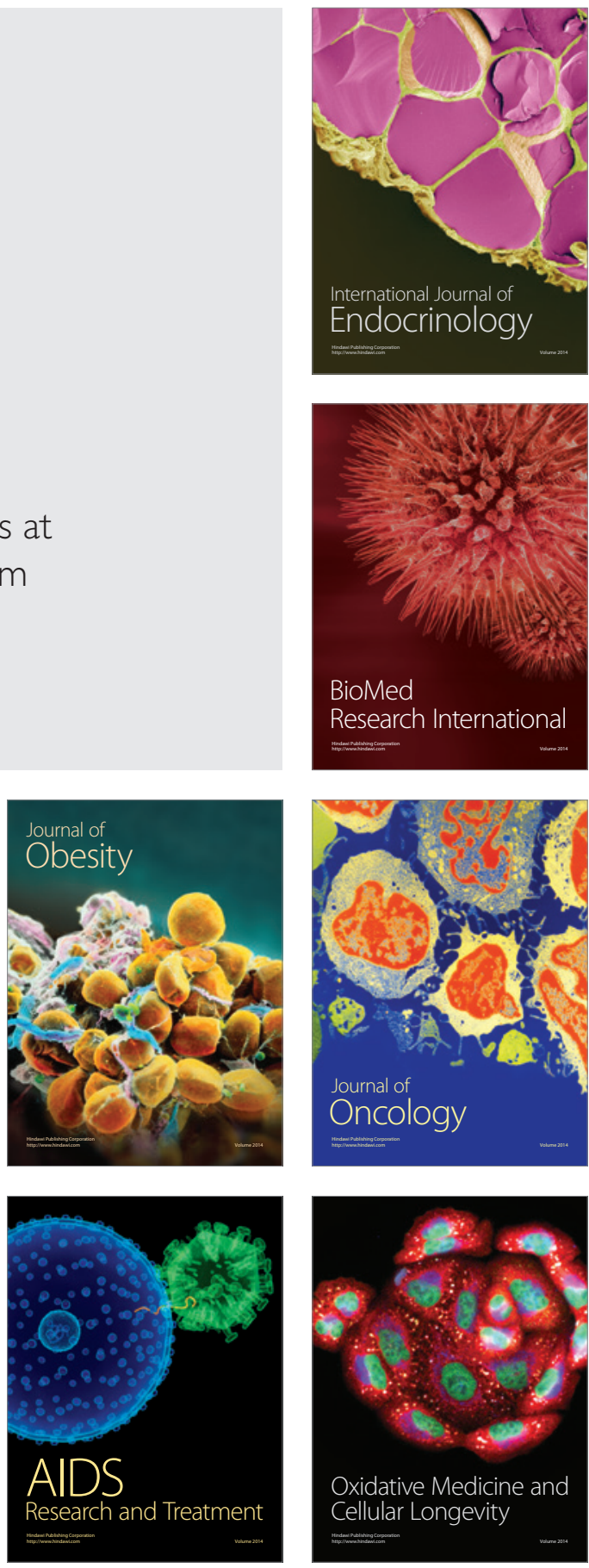